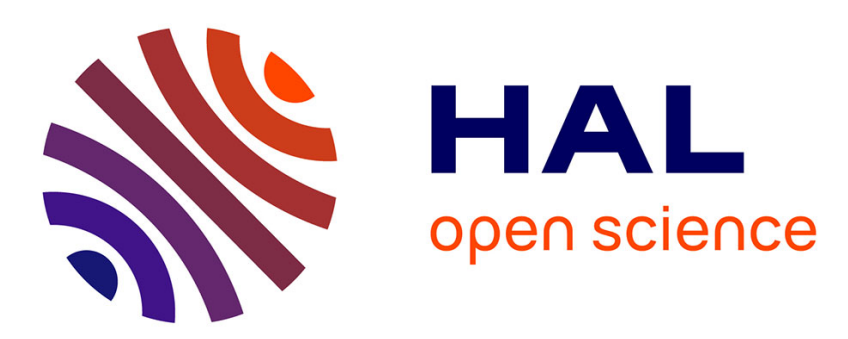

\title{
Gender Interaction in Teams: Experimental Evidence on Performance and Punishment Behavior
}

\author{
Seeun Jung, Radu Vranceanu
}

\section{To cite this version:}

Seeun Jung, Radu Vranceanu. Gender Interaction in Teams: Experimental Evidence on Performance and Punishment Behavior. 2015. hal-01171161

\section{HAL Id: hal-01171161 \\ https://essec.hal.science/hal-01171161}

Preprint submitted on 3 Jul 2015

HAL is a multi-disciplinary open access archive for the deposit and dissemination of scientific research documents, whether they are published or not. The documents may come from teaching and research institutions in France or abroad, or from public or private research centers.
L'archive ouverte pluridisciplinaire HAL, est destinée au dépôt et à la diffusion de documents scientifiques de niveau recherche, publiés ou non, émanant des établissements d'enseignement et de recherche français ou étrangers, des laboratoires publics ou privés. 


\title{
Gender Interaction in Teams: Experimental Evidence on Performance and Punishment Behavior
}

\author{
RESEARCH CENTER \\ ESSEC Working Paper 1513
}

2015

Seeun Jung

Radu Vranceanu

E 


\title{
Gender Interaction in Teams: Experimental Evidence on Performance and Punishment Behavior
}

\author{
Seeun Jung* \& Radu Vranceanu ${ }^{\dagger}$
}

June 25, 2015

\begin{abstract}
This paper reports results from a real-effort experiment in which men and women are paired to form a two-member team and asked to execute a real-effort task. Each participant receives an equal share of the team's output. Workers who perform better than their partner can punish him/her by imposing a fine. We manipulate the teams' gender composition (man-man, man-woman, and woman-woman) to analyze whether an individual's performance and sanctioning behavior depends on his/her gender and the gender interaction within the team. The data show that, on average, men perform slightly better than women. A man's performance will deteriorate when paired with a woman, while a woman's performance will improve when paired with a woman. When underperforming, women are sanctioned more often and more heavily than men; if sanctioned, men tend to improve their performance, while women's performance does not change.

Keywords: Gender studies, Real-effort task, Team production, Performance, Punishment, Discrimination.

JEL Classification: M52; J16; C91
\end{abstract}

\section{Introduction}

The organization of economic activity within firms relies on teams of individuals who jointly produce goods and services. In many cases, the team supervisor cannot observe the contribution of each individual to the team's output. Hence in practice many firms will resort to team-based incentives to reward their employees (Lawler and Mohrman (2003); Boning et al. (2007)). Economists note that such compensation schemes can be inefficient; if every team member relying on the efforts of his partners reduces his own effort, in equilibrium, all team members will follow the same strategy and output collapses. Several theoretical papers argued that such free-riding behavior can be contained if the group can develop internal monitoring processes and can punish defectors by taking actions that will diminish defectors' payoffs. ${ }^{1}$ Such sanctions need not be monetary; mockery, intimidation and social exclusion of those who deviate from the group's norm are ubiquitous phenomena

*ESSEC Business School and THEMA. PB 50105, 95021 Cergy, France. E-mail: jung@essec.edu

${ }^{\dagger}$ ESSEC Business School and THEMA. PB 50105, 95021 Cergy, France. E-mail: vranceanu@essec.fr

${ }^{1}$ See for instance: Alchian and Demsetz (1972), Holmstrom (1982), McAfee and McMillan (1991), Itoh (1991), Kandel and Lazear (1992), Legros and Matthews (1993), Barron et al. (1997), Che and Yoo (2001). 
in modern organizations (Fehr and Gächter (2000)). However, psychologists warn that beyond the "discipline" effect, sanctions might entail undesired outcomes, because they generate negative emotions that might hamper performance, which has been termed the "motivation crowding-out" effect (for a survey, see Frey and Jegen (2001) and Festré and Garrouste (2014)). ${ }^{2}$

One important characteristic of production teams is their gender composition. Men and women might present different behavioral responses to incentives (positive or negative), and more important, their behavior may change depending on the gender with which they are paired. Whether a group's gender composition affects the performance of the group members is an important research question, especially for the management of the firms that are moving from all-man to mixed gender work-teams. Yet, as Kuhn and Villeval (2013) emphasize, "compared to the literature on gender and tournaments, the economics literature on gender and teams is sparse". The aim of the present paper is to contribute to the literature on gender discrimination in the workplace by studying performance and punishment behavior of workers paired with a same/different gender partner in a real-effort task.

Some recent empirical studies have shown that the gender composition of a team has an impact on the team's performance. For instance, Apesteguia et al. (2012) analyze information from a large database on a well-known business game played by self-selected teams of three students (StratX-l'Oréal). They show that, even when controlling for personal characteristics, all-women teams perform worse than all-men and mixed teams. A similar result is obtained by Lamiraud and Vranceanu (2014) using panel data from a different business game (Kalystée-l'Oréal) with random allocation of students to teams of five. In their study, all-men and mixed teams with a majority of women perform the best. Hoogendoorn et al. (2013) collect data on companies created and operated for one academic year by students enrolled in the entrepreneurship program of the Amsterdam College of Applied Sciences and find that business teams with an equal gender mix perform better than male-dominated teams in terms of profits and sales. In a different setting, Eckel and Füllbrunn (2015) study identical experimental assets markets in separate groups of men and groups of women; they show that chances of price bubbles to appear are much higher in markets with men traders, than in markets with women traders.

There a significant body of literature on gender differences in the workplace to which our work can be related. Acknowledging that men-women wage discrimination, discriminatory hiring and promotion processes unfavorable to women are still ubiquitous in the Western countries, in the last few years experimental economists aimed at revealing the underlying factors at the origin of these worrisome phenomena (see the survey by Azmat and Petrongolo (2014)). At the individual level, it is generally accepted now that women are more averse to risk than men (Eckel and Grossman (2008); Croson and Gneezy (2009)). ${ }^{3}$ If risk taking is a factor of success in many well-paid jobs (traders, CEOs), this would explain the employers' preference for men. Another well-documented observed behavior is that women are more averse to competition than men (Niederle and Vesterlund (2007, 2011); Croson and Gneezy (2009)). ${ }^{4}$ In this case, men reaching higher positions

\footnotetext{
${ }^{2}$ The potentially detrimental effect of sanctions and the stimulating effect of refraining from imposing sanctions, have already been emphasized by experimental economists who studied the principal/agent game (Dickinson and Villeval (2008); Kirstein (2008)), the trust game (Fehr and List (2004); Fehr and Rockenbach (2003); Houser et al. (2008)) or the ultimatum game (Gneezy (2003)).

${ }^{3}$ This result has recently been challenged based on the weakness of the statistical tests used to confirm it (Filippin and Crosetto (2014)).

${ }^{4}$ Niederle and Vesterlund (2007) build their analysis on two-stage real-effort task experiment (solving
} 
in a company hierarchy (and high wages) might be explained by men's higher propensity to "fight" for that positions. Kuhn and Villeval (2013) use a real-effort experiment to analyze gender differences regarding self-selection in teams with the compensation as an equal share of the team's output. ${ }^{5}$ They show that women have a preference for team work (a cooperative environment), whereas men would prefer individual tasks (a more competitive environment). Ortmann and Tichy (1999) use a Prisoner's Dilemma game to show that women have a greater propensity to cooperate than men, but their desire to cooperate fades when the game is repeated. Whether such gender specific traits (aversion to risk or aversion to competition) are innate or educated, the question is still open to debate.

Other papers, closer to ours, study how gender interaction in groups affects on individual behavior. It has been argued by psychologists that women may exhibit greater solidarity with women than with men (Tajfel (1981)) and, conversely, that women may regard other women as competitors (Buss (1998); Campbell (1999); Kanazawa (2005)). Gneezy (2003) reports that, when the compensation scheme becomes more competitive, women increase their performance only when they compete with women, but not when they compete with men. Differences in how men (women) react when paired with same (opposite) gender partners have been observed in standard Ultimatum games. Eckel and Grossman (2001) find that women make more generous offers than men, that offers made by women do not depend on the partner's gender, and that they are more likely to be accepted. Solnick (2001) finds that women and men do similar offers, but women are more demanding than men when the opposer is female, and less demanding when the opposer is male. In a $2 \times 2$ design male/female, origin of Jewish immigrants to Israel (Ashkenazic / Sephardic), Fershtman and Gneezy (2001) found that males (but not females) discriminated against Ashkenazic men (but not against women), offering them less than they did to Sephardic men.

The Dictator game is also interesting for the study of gender interactions since it rules out strategic behavior. Ben-Ner et al. (2004) conduct several dictator game experiments in which women and men are allowed to divide ten dollars with a completely unknown person, or a person of a known gender. They found that women give systematically less to women than to men and persons of an unknown gender. There is no clear evidence on whether women give more or less than men in dictator games, and whether the gifts depend on the gender of the recipient (Azmat and Petrongolo (2014)). Dufwenberg and Muren (2006) show that women receive more favorable treatment than men in the dictator game.

In order to analyze how the team gender composition affects on performance and sanctioning behavior of individuals in the group, we extend the real-effort experiment introduced by Mohnen et al. (2008) to allow for explicit peer punishment. In this experiment, the compensation scheme is cooperative, being similar to the team-based pay as applied by many contemporary firms. As a particular development in this paper, at the outset of the experiment participants were randomly assigned to mixed gender, all-men and all-women teams, in a standard between-subjects design, where a subject cannot participate in more than one experimental session. We used a "smooth" communication

mazes). Although there are no gender differences in performance in the first stage, in the next stage, men select a tournament payment scheme rather than piece-wise pay twice as often as do women.

${ }^{5}$ Their experiment builds on a coding task. When they choose team production, subjects guess the gender of the partner by learning his/her first name. Partners on teams receive an equal split of the joint output. 
method to ensure that team members were aware of their partner's gender while at the same time preserving the anonymity of the participants. Thus, this experiment aims at capturing the "genuine gender effect", independent on any emotions and social stances that would develop if partners can establish eye contact or communicate. Participants were asked to count the $7 \mathrm{~s}$ in blocs of figures successively displayed on the computer screen during six successive rounds of four minutes each. This task was introduced by Mohnen et al. (2008) and Pokorny (2008) who note that it is interesting for experimental research because it does not require any particular skill or computing ability. At each round, individuals receive an equal share of the team's output, which is proxied by the total number of correct answers. ${ }^{6}$ In our experiment, as in Mohnen et al. (2008), if a participant chooses to rest, he/she can press a button, and the screen is blocked for a 20s period for which he/she receives a small lump-sum payment (as the opportunity cost of working). Payoffs are calibrated such that without punishment individuals have an incentive to free ride (they are paid for resting). However, in this paper, the best performer on a team has the option to punish the less productive partner by applying a monetary sanction (Vranceanu et al. (2014)).

Taking stock on the existing literature on gender composition and team performance which shows that all-women teams record relatively poorer performances than mixed teams, we might make the hypothesis according to which, when a women is teamed with a women, her performance would deteriorate. In line with the observed discrimination in the workplace, we might hypothesize that, at equivalent performance gap, women are sanctioned more often than men. Would men and women respond differently to a sanction? Rask and Tiefenthaler (2008) analyzed why relatively fewer women decide to major in economics; they found that women's decision to drop these classes is motivated by the poor grades they receive in the introductory courses in economics, whereas men are less discouraged by the negative signal provided by the same poor grades.

In essence, our results indicate that, in this specific task, on average, men perform (slightly) better than women. In teams, if a men is teamed with a women his performance will deteriorate, yet, contrary to what we would expect, if a women is teamed with another women her performance will improve. When under-performing, women are sanctioned more frequently than men. Finally, in line with the findings by Rask and Tiefenthaler (2008), when sanctioned, men's performance improves whereas women's performance does not, as if in the case of women a strong motivation crowding out effect will offset the discipline effect. ${ }^{7}$

The paper is organized as follows: The next section introduces the experimental design. Section 3 presents the data and the main descriptive statistics. Section 4 introduces several regression models. The final section presents our conclusions and provides some managerial implications, with all of the caveats related to the challenge of extrapolating from such simple experiments conclusions deemed to be relevant for managers in "nuts and bolts" firms.

\footnotetext{
${ }^{6}$ Notice that this compensation scheme should encourage cooperation, as in the experiment by Kuhn and Villeval (2013), and would part from the competitive environment specific to the experiments by Gneezy (2003) or Niederle and Vesterlund (2007, 2011), in which individual pay is based on a tournament.

${ }^{7}$ We also used the dataset of Vranceanu et al. (2014) to check that there is no gender effect in groups that play a similar real-effort task without knowing the gender of the partner.
} 


\section{Experimental design}

All subjects were recruited from the student population of the ESSEC Business School (France), who answered an advertisement for paid decision experiments. ${ }^{8}$ Five sessions were organized at the ESSEC Experimental Lab with a total of 100 subjects in October 2014, November 2014 and January 2015 (Table 1). At the beginning of the experiment, subjects are matched in pairs at random. The team composition is not changed across rounds. Interaction is anonymous, and hence subjects do not know who their partners are. They play the game on a computer screen and cannot establish eye contact with one another; instructions (provided in the Appendix) and data collection are computerized; the program was developed using z-Tree (Fischbacher (2007)). ${ }^{9}$ Payoffs are denominated in Experimental Currency Units (ECU), with an exchange rate $100 \mathrm{ECU}=2.5$ Euros.

In a typical round, subjects are asked to count the number of $7 \mathrm{~s}$ in blocks of random numbers, successively displayed on the computer screen over four minutes (Mohnen et al. (2008); Pokorny (2008); Vranceanu et al. (2014)). The typical bloc has 30 columns and 6 rows (see Appendix); in each bloc, the number of $7 \mathrm{~s}$ varies at random between 11 and 24 , with an average of 18 . Note that difficulty of the task depends on the total number of figures in a bloc (180), and not on the number of $7 \mathrm{~s}$, and thus it should not vary from one bloc to another. At the beginning of the experiment, the computer displays the first block. When the participant finishes to count, he/she indicates the number of $7 \mathrm{~s}$ in a box, than clicks on "validate"; the computer records the answer (and checks it), then displays another block of figures. Thus the number of blocks displayed during the four minutes of a representative round depends on the speed of counting of the participant. Note that instead of counting, the participant has also the alternative to rest; if he presses the button "time-out", the computer cancels the count task by displaying a neutral screen (Essec logo) for 20 seconds. ${ }^{10}$ If the participant chooses this option, he will earn a small lump-sum (6 ECU). This second option can be viewed as an opportunity cost of working. The experiment comprises six identical 4-minute rounds.

When the four minutes elapse, the round is over and participants learn the number of correct answers they have provided, as well as the number of correct answers provided by their partner. We choose on purpose to disclose only the key performance measure of the partner, which is his/her number of correct answers, and not the number of blocks worked on or the number of times the time-out button was pressed. This information structure of the experiment aims to account for real life situations where partners in team can observe the essentials of the contribution of the team mates to the team's output, but do not know "everything" about the partner. In particular, it is reasonable to think that partners in a "real" team cannot disentangle which of a higher effort and or better skills explains a higher individual output. Of course, results of the paper depend on the information structure of the experiment, and, should we decide to provide more information to partners, results might be different.

Then, the player who out-performed (i.e., provided more correct answers than the other) is asked whether he/she wishes to impose a penalty on his/her partner. If he/she answers "yes", he/she can penalize the other player by an amount $p$, where $p$ varies

\footnotetext{
${ }^{8}$ As "Grande Ecole" students, this group is relatively homogenous in terms of computing and intellectual abilities, age and educational background. It should be acknowledged that students are admitted at ESSEC after succeeding in a very competitive national exam, with a demanding test in mathematics.

${ }^{9}$ The computer program was developed by Delphine Dubart at the ESSEC Experimental Lab.

${ }^{10}$ The time-out button is deactivated 20 seconds before the end of the round (this is the average time needed to count the $7 \mathrm{~s}$ in the last block of numbers).
} 
between 1 and 30 ECUs. Punishment is costly: each unit of sanction entails a cost of 0.30 ECUs for the punisher. Such a linear punishment technology, involving a constant cost per unit of punishment has been used in many other studies (Fehr and Gächter (2000); Falk and Fischbacher (2005); Nikiforakis and Normann (2008)). In the event of equal performance, no penalty can be imposed. After the punishment decision is made, players learn their ECU payoff for the round.

For each round, a player's reward is calculated according to a simple rule (1). Let us consider a team composed of players $i$ and $j$. Let $N_{i t}$ (respectively $N_{j t}$ ) be the number of correct answers provided by the individual $j$ (respectively $j$ ) in round $t$. Without any loss of generality, let us assume that $N_{j t}>N_{i t}$. The first term is a linear function in the sum of correct answers provided by the two players. Next term, is the payoff associated to the breaks; if the participant pressed the time-out button for $k$ times, he/she also obtains the associated payoff of $k$ times 6 ECU. Finally, since $N_{j t}>N_{i t}$, individual $j$ can punish individual $i$ by imposing a penalty $p_{j i t} \in[0 ; 30]$. Compensation functions for each player are:

$$
\left\{\begin{array}{l}
Z_{i t}=10 \frac{N_{i t}+N_{j t}}{2}+6 k_{i t}-p_{j i t} \\
Z_{j t}=10 \frac{N_{i t}+N_{j t}}{2}+6 k_{j t}-0.3 p_{j i t}
\end{array} .\right.
$$

Payments for all rounds will be converted into cash and paid at the end of the experiment.

Note that the parameters of the game were selected such that, without punishment, free-riding (i.e., pressing the time-out button) is the dominant strategy. An individual who makes a normal effort to count the $7 \mathrm{~s}$ can provide a correct answer in 20 seconds on average. If the other player does the same, both would earn 10 ECUs. However, if one presses the time-out button (blocks the screen and rests for 20 seconds) while the other works and provides a correct answer, the player who free rides obtains 11 ECUs (and the other receives 5ECUs). Clearly, 11 ECUs and resting is better than 10 ECUs and executing the boring task. If both players free ride and press the time-out button, they each get 6 ECUs.

As already mentioned, the paper aims at analyzing the impact of the teams' gender composition on individual performance, and on punishment behavior. To do so, we manipulate the gender composition of the groups, to create mixed teams, man-man teams and woman-woman teams. Subjects signed up for a specific session. We ensure that students who participated in one treatment could not participate in another treatment.

It was important to ensure that team members were aware of the gender of their partner, without conveying this information in a salient way. We thus organized sessions to which only men (only women) were invited, and mixed-gender sessions with an equal number of men and women. In the single-gender sessions participants can clearly observe that only men (women) are present, so they must be paired with a same-gender partner. In the mixed gender sessions, all pairs were mixed but individuals cannot observed it directly. Thus, to convey information on the gender of the partner in a non-directive way and without relaxing anonymity, at the beginning of the experiment, participants were asked to complete an electronic form concerning their "personal characteristics" - age, gender and level of education. Immediately thereafter, the information was communicated to the other team member as "basic information" about his/her partner. In our student population, ages and levels of education are not differentiating characteristics. The only distinctive characteristic was gender, but no emphasis was placed on this. At the end of the experiment, we asked students whether they could recall the gender of their partner, and if so, what the gender was; 2 out of 100 subjects (one man and one women) could 
Table 1: Sessions and Treatments

\begin{tabular}{lccc}
\hline Date & Treatment & Number of Subjects & Number of Teams \\
\hline Oct 23 2014 & WW & 26 & 13 \\
Nov 7 2014 & MW & 24 & 12 \\
Nov 18 2014 & MM & 18 & 9 \\
Dec 5 2014 & MW & 18 & 9 \\
Jan 14 2014 & MM & 14 & 7 \\
\hline
\end{tabular}

not recall this. This is a good indication that, while students knew the gender of their partner, they did not focus on it.

Table 1 presents the distribution of subjects with respect to sessions and treatments: On average, the experiment took approximately 50 minutes. Subjects earned 15.2 Euros on average.

\section{$3 \quad$ Data and basic statistics}

Among the 100 students who participated in the experiment, 47 were female. Thus 47 individuals were paired with a female partner. Each subject performed the task for 6 rounds; the dataset thus includes 600 observations.

Table 2 reports the summary statistics, for the whole sample (first panel) and separately for the population of men and women (second and third panels).

There are two key indicator variables that capture the gender profile of individuals and teams - FE ( 1 if subject is a woman, 0 if it is a man) and $F E p$ ( 1 if the partner is a woman, 0 if it is man). Their interaction term $F E \times F E p$ is also useful (by construction, it takes the value 1 if the subject is a woman and is paired with a woman). Detailed definitions of all variables are provided in the Appendix.

\subsection{Individual performance}

The key measure of performance is the number correct answers provided by individual $i$ in round $t$, denoted by $N R A_{i t}$. The full-sample average performance per round is approximately 9.90 correct answers, with men performing slightly better than women (10.26 vs. 9.86); the difference is nonetheless statistically significant, a result that contrasts with findings by Kuhn and Villeval (2013) or Niederle and Vesterlund (2007) who observed no gender difference in performance, using various real-effort tasks (coding and solving mazes, respectively).

Figure 1 simply presents the evolution of the number of correct answers across rounds for both men and women. In all rounds men performed better than women. We can also observe that performance improves from rounds 1 to 5 indicating the presence of some learning effect (Benndorf et al. (2014)). One would expect the latter to fade away across rounds, being offset by fatigue and boredom, which appear to have set in round 6 when performance declines for both men and women. However, because our experiment builds on a between-subjects design, the learning effect should not be a problem.

A less precise measure of performance, but one independent of the ability to count correctly, is the number of blocks counted by individual $i$ in round $t$, whatever the score 
Table 2: Summary Statistics

\begin{tabular}{|c|c|c|c|c|c|}
\hline & 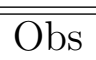 & Mean & $\overline{\mathrm{Sd}}$ & Min & $\overline{\mathrm{Max}}$ \\
\hline $\mathrm{FE}$ & 100 & 0.47 & 0.50 & 0 & 1 \\
\hline FEp & 100 & 0.47 & 0.50 & 0 & 1 \\
\hline FExFEp & 100 & 0.26 & 0.44 & 0 & 1 \\
\hline NRA & 600 & 9.86 & 3.28 & 0 & 18 \\
\hline NBLOCK & 600 & 12.00 & 4.88 & 1 & 43 \\
\hline NTIMEOUT & 600 & 0.62 & 1.50 & 0 & 11 \\
\hline DIFSC & 600 & 0.00 & 4.04 & -11 & 11 \\
\hline SANC & 275 & 0.19 & 0.40 & 0 & 1 \\
\hline MSANC & 275 & 2.87 & 7.49 & 0 & 30 \\
\hline $\mathrm{MSANC}$ cond. $\mathrm{SANC}=1$ & 53 & 14.91 & 10.62 & 1 & 30 \\
\hline \multicolumn{6}{|c|}{ Male Sample } \\
\hline FEp & 53 & 0.40 & 0.49 & 0 & 1 \\
\hline NRA & 318 & 10.26 & 3.43 & 0 & 18 \\
\hline NBLOCK & 318 & 13.00 & 5.88 & 1 & 43 \\
\hline NTIMEOUT & 318 & 0.64 & 1.72 & 0 & 11 \\
\hline DIFSC & 318 & 0.60 & 4.29 & -11 & 11 \\
\hline SANC & 171 & 0.22 & 0.41 & 0 & 1 \\
\hline MSANC & 171 & 3.36 & 8.21 & 0 & 30 \\
\hline $\mathrm{MSANC}$ cond. $\mathrm{SANC}=1$ & 37 & 15.51 & 11.16 & 1 & 30 \\
\hline \multicolumn{6}{|c|}{ Female Sample } \\
\hline FEp & 47 & 0.55 & 0.50 & 0 & 1 \\
\hline NRA & 282 & $9.41^{* * *}$ & 3.04 & 1 & 17 \\
\hline NBLOCK & 282 & $10.88^{* * *}$ & 3.05 & 1 & 22 \\
\hline NTIMEOUT & 282 & 0.59 & 1.21 & 0 & 8 \\
\hline DIFSC & 282 & $-0.67 * * *$ & 3.62 & -11 & 10 \\
\hline SANC & 104 & 0.15 & 0.36 & 0 & 1 \\
\hline MSANC & 104 & 2.08 & 6.08 & 0 & 30 \\
\hline $\mathrm{MSANC}$ cond. $\mathrm{SANC}=1$ & 16 & 13.50 & 9.44 & 2 & 30 \\
\hline
\end{tabular}

${ }^{*} \mathrm{p}<0.10,{ }^{* *} \mathrm{p}<0.05,{ }^{* * *} \mathrm{p}<0.01$ of T-test between genders 
Figure 1: Performance Evolution over Rounds by Gender

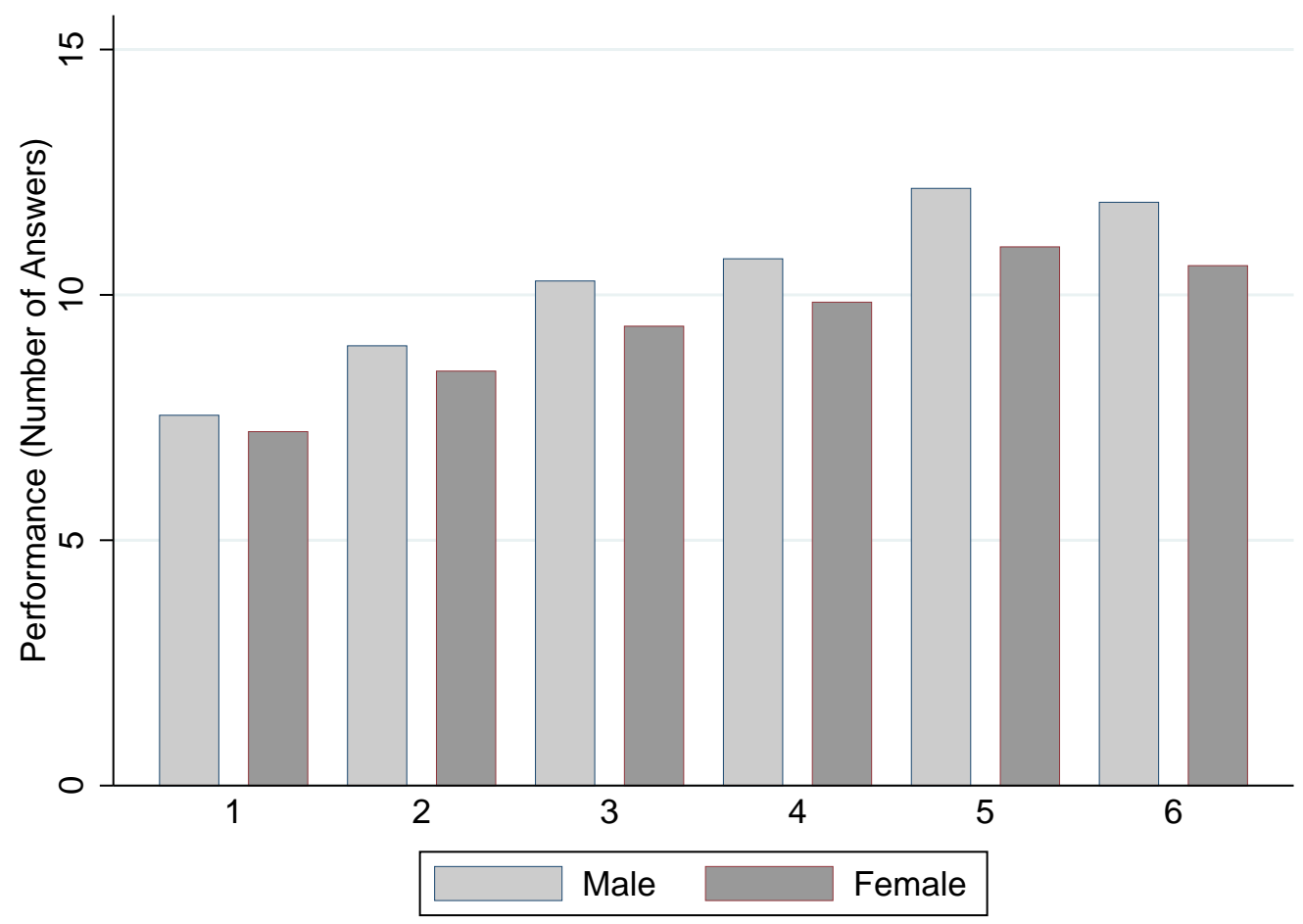

(which can be correct or not), NBLOCK $K_{i t}$.

From Table 2, we observe that on average participants counted 12 blocks per round, with men counting 13 and women counting 10.88 blocks, the difference being statistically significant.

Using these data, it is difficult to determine whether the gender differences in performance as measured by the two former measures stem form differences in abilities (attention and speed of counting) or the deliberate choice to free-ride. Some indication is provided by the number of times that a participant chose to press the time-out button (NTIMEOUT), which is a good proxy for free riding behavior. With respect to this measure, the difference between men and women is statistically insignificant. Men tend to take more time-outs (0.64) than women (0.59), while their counting performance is better. This suggests that the gender differences in performance observed in this experiment are driven by counting skills and not by alleged shirking of female subjects.

\subsection{Gender interaction and individual performance}

Table 3, Figures 4 and 5 decompose the individual performance and free-riding measures (NRA and NTIMEOUT) (as a total for the whole six rounds of the experiment), in terms of gender compositions: depending on who (a male or a female) was paired with whom (a male or a female). 
Table 3: Summary Statistics by Gender Composition

\begin{tabular}{lccccc}
\hline \hline & Obs & Mean & Sd & Min & Max \\
\cline { 1 - 5 } \multicolumn{1}{c}{ Performance (Number of Correct } & Answers) & \\
Man with Man & 192 & 10.55 & 3.32 & 1 & 18 \\
Man with Woman & 252 & 9.08 & 3.50 & 0 & 18 \\
Woman with Woman W & 156 & 10.28 & 2.54 & 4 & 17 \\
Woman with Man & 126 & 8.33 & 3.27 & 1 & 16 \\
\multicolumn{7}{l}{ Free-Riding (Number of Time-out } & Button Pressed) & \\
Man with Man Partner & 192 & 0.43 & 1.07 & 0 & 7 \\
Man with Woman & 252 & 0.92 & 2.03 & 0 & 11 \\
Woman with Woman & 156 & 0.35 & 0.61 & 0 & 3 \\
Woman with Man & 126 & 0.89 & 1.64 & 0 & 8 \\
\hline \hline
\end{tabular}

Figure 2: Performance by Gender Composition

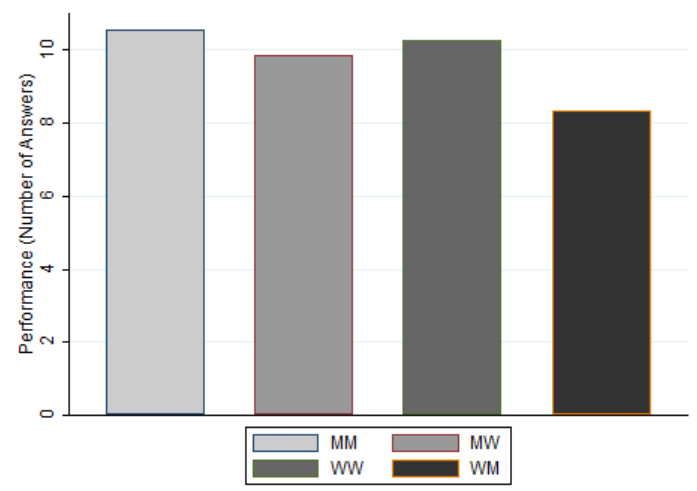

Figure 3: Free-Riding Behavior by Gender Composition

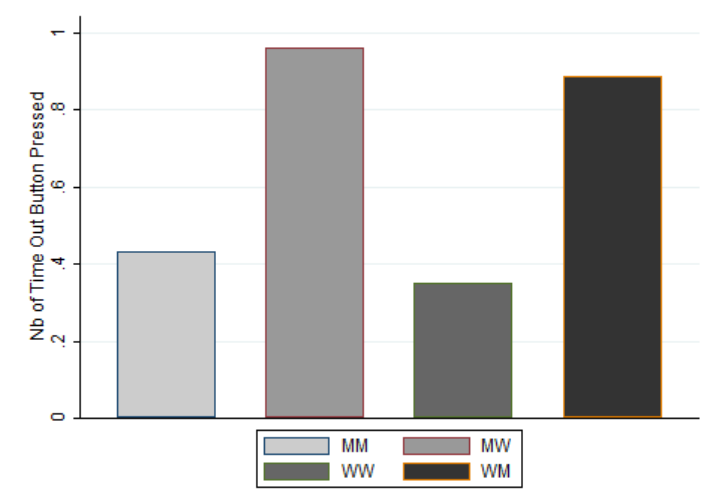

These basic statistics suggest that: ${ }^{11}$

Men paired with another man have the best individual performance (number of right answers), and also a low propensity to free-ride. When paired with a woman, men's (individual) performance will deteriorate and free-riding will increase.

However, the individual performance of women teamed with a woman is quite strong, and they less prone to free-ride. Yet, when women are paired with a man, their performance will decline sharply and free-riding will edge-up.

\subsection{Sanctioning behavior}

Another important measure is the difference in the number of correct answers between the two partners $(i, j)$ in a round $t, D I F S C_{t}=N R A_{i t}-N R A_{j t}$. By definition of this variable, the full-sample average difference in performance between partners is 0 (a positive performance of individual $i$ with respect to $j$ is offset by the negative performance of $j$ with respect to $i$ ). Simple comparisons of the data in the second and third panels in Table

\footnotetext{
${ }^{11}$ In the next section, regression models will allow to show that these findings are robust to various addtional controls.
} 
2 indicate that men perform significantly better than women.

The sanctioning behavior is captured by two measures. From the design section, we know that in any round the best performer in a team can, if he/she wishes, impose a monetary sanction on his/her partner in the range [0;30] ECU, at a cost of 0.30ECU per one ECU of penalty. Sanctions could be applied in 275 cases in which one individual performed strictly better than the other. Conditional on performing better, $19 \%$ of individuals impose penalties on their partners $(S A N C=1)$, for an average sanction amount $(M S A N C)$ equal to $2.64 \mathrm{ECU}$. Conditional on imposing a fine to the partner, the average amount of the sanction is $14.91 \mathrm{ECU}$.

Figures 4 and 5 depict the evolution of the sanction amount across rounds by gender. In the second round, individuals tend to impose the highest fines, which gradually decrease over time. One interesting point is that individuals still impose sanctions in the last round despite it being costly. An explanation for this phenomenon was provided by Camerer and Fehr (2006) who acknowledged the existence of a large proportion of "strong reciprocators", i.e., individuals who show a combination of altruistic reward and altruistic punishment, defined as the propensity to impose sanctions on others for norm violations. Such strong reciprocators will bear the cost of imposing punishment even if they gain no individual benefit.

Figure 4: Frequency of Applying Sanctions across Rounds by Gender

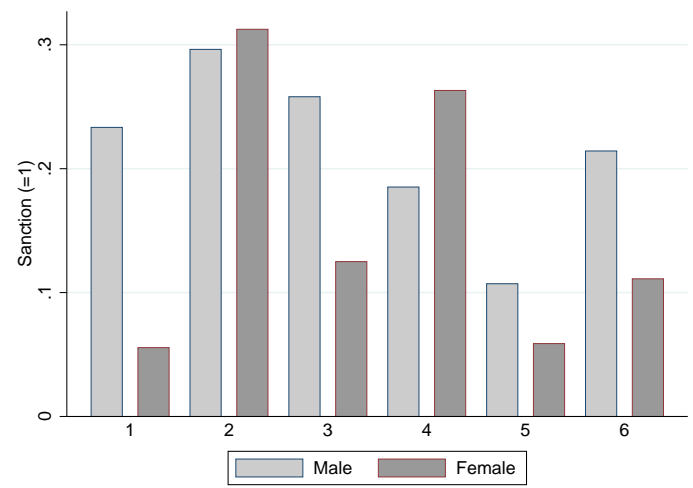

Figure 5: Average Amount of Sanction across Rounds by Gender

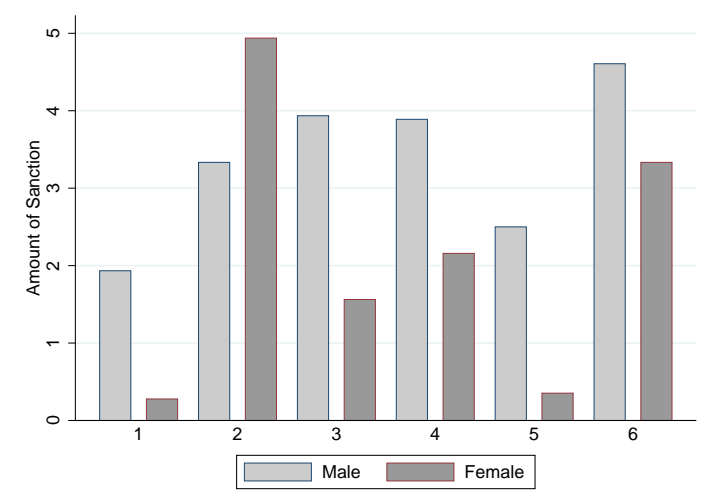

Simple comparisons of the data in the second and third panels of Table 2 show that men tend to apply sanctions more often than women (22\% compared to $15 \%$ ), and charge on average a higher amount than women (15.51 ECUs compared to 13.50 ECUs) conditional on imposing a fine to the partner.

\subsection{Gender interaction and sanction behavior}

Table 4, Figures 6 and 7 show the frequency of sanctioning and the average amount of the sanction for each gender type of subject (male, female) depending on the gender of the partner (male, female), for the whole six rounds of the experiment. 
Table 4: Summary Statistics of Sanction by Gender Composition

\begin{tabular}{lccccc}
\hline \hline & Obs & Mean & Sd & Min & Max \\
\hline \multirow{2}{*}{ Manction Frequency } & & & \\
\cline { 2 - 5 } Man with Man Woman & 87 & 0.11 & 0.32 & 0 & 1 \\
Woman with Woman & 64 & 0.32 & 0.47 & 0 & 1 \\
Woman with Man & 35 & 0.19 & 0.39 & 0 & 1 \\
& & 0.09 & 0.28 & 0 & 1
\end{tabular}

\begin{tabular}{lccccc}
\multicolumn{7}{c}{ Amount of Sanction cond. SANC $=1$} & \\
\cline { 2 - 5 } Man with Man & 10 & 10.80 & 9.46 & 2 & 30 \\
Man with Woman & 27 & 17.26 & 11.39 & 1 & 30 \\
Woman with Woman & 13 & 12.38 & 9.28 & 2 & 30 \\
Woman with Man & 3 & 18.33 & 10.41 & 10 & 30 \\
\hline \hline
\end{tabular}

Figure 6: Sanction Frequency by Gender Composition

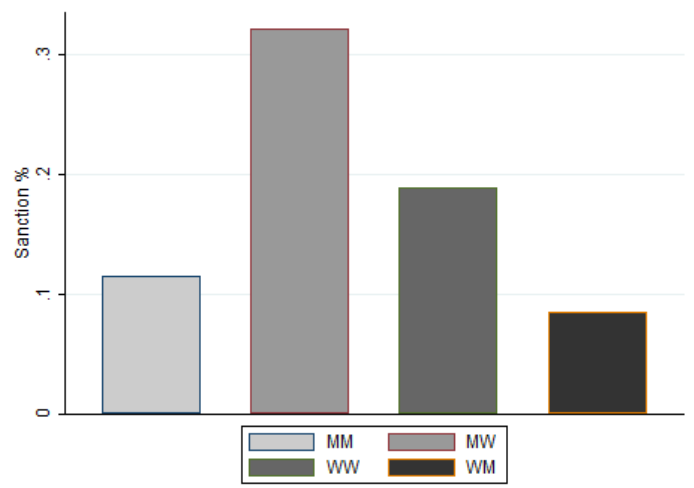

Figure 7: Amount of Sanction cond. $\mathrm{SANC}=1$ by Gender Composition

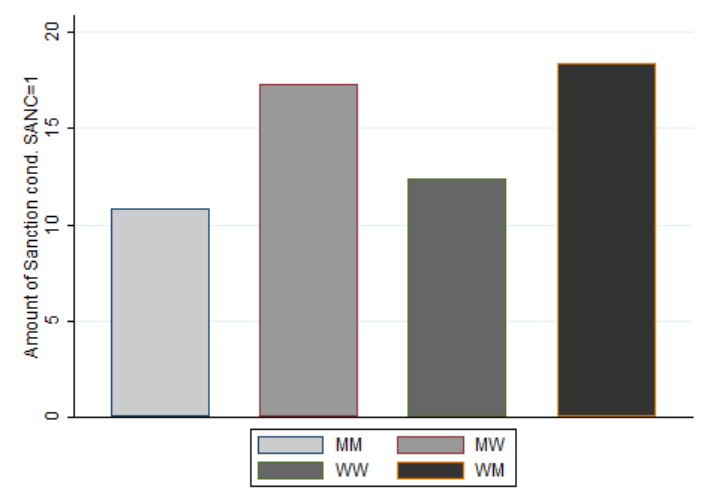

As a key finding, it turns out that on average men will impose higher sanctions on their woman partner than on a man partner (10.8 vs. 17.26), and women will impose higher sanctions on men than on women (10.41 vs. 9.28).

\subsection{Pairwise correlations}

Table 5 presents the pairwise correlation matrix of our variables of interest. The two measures of performance ( $N R A$ and $N B L O C K$ ) exhibit a high and significant correlation (0.63). Thus, for the sake of parsimony, in the following analyses we will consider only the number of correct answers as a measure of performance.

The number of time-outs is negatively and significantly correlated (-0.24) with the number of correct answers produced by an individual. As expected, a higher difference in scores (tantamount to lower relative performance) is associated with a higher frequency of punishment and a higher sanction amount.

In line with the above mentioned findings, while women tend to sanction their partner less frequently than men do (although the difference is insignificant) and charge a lower amount, they tend to be sanctioned more often, and be charged a higher amount (as shown by the positive and significant coefficient between $F E p$ and $S A N C$ (respectively $M S A N C)$ ). 
Table 5: Pairwise Correlation Matrix of Variables of Interest

\begin{tabular}{lcccccccc}
\hline \hline & FE & FEp & NRA & NBLOCK & NTIMEOUT & DIFSC & SANC & MSANC \\
\hline FE & 1 & & & & & & & \\
FEp & $0.157^{* * *}$ & 1 & & & & & & \\
NRA & $-0.130^{* *}$ & 0.0632 & 1 & & & & & \\
NBLOCK & $-0.218^{* * *}$ & 0.0285 & $0.633^{* * *}$ & 1 & & & & \\
NTIMEOUT & -0.0164 & 0.00363 & $-0.241^{* * *}$ & 0.0142 & 1 & & & \\
DIFSC & $-0.157^{* * *}$ & $0.157^{* * *}$ & $0.615^{* * *}$ & $0.339^{* * *}$ & $-0.167^{* * *}$ & 1 & & \\
SANC & -0.0769 & $0.195^{* *}$ & -0.107 & 0.0375 & 0.117 & $0.227^{* * *}$ & 1 & \\
MSANC & -0.0830 & $0.184^{* *}$ & 0.0117 & $0.139^{*}$ & 0.105 & $0.306^{* * *}$ & $0.786^{* * *}$ & 1 \\
\hline \hline${ }^{*} \mathrm{p}<0.10,{ }^{* *} \mathrm{p}<0.05,{ }^{* * *} \mathrm{p}<0.01$ & & & & & & & & \\
\hline
\end{tabular}

Several regression models will allow us to move beyond these elementary findings. Throughout our experiments, there was one male and one female participants who could not recall their partner's gender. We will exclude these two persons from subsequent analyses.

\section{Regression analysis}

\subsection{The general regression model}

We develop several regression models aiming to explain the determinants of individual performance, free-riding, and sanctioning/sanctioned behavior. Since the focus of the analysis falls on the effects brought about by the gender composition of the teams, models use as gender-specific covariates the two indicator variables as mentioned before: $F E$ (1 if subject is a woman, 0 if the subject is a man) and $F E p$ ( 1 if the partner is a woman, 0 if the partner is a man), as well as their interaction term $(F E \times F E p)$.

In a general form, the random-effects models estimated below can be written as:

$$
y_{i t}=\beta^{\prime} X_{i t}+\alpha_{1} F E+\alpha_{2} F E p+\alpha_{3} F E \times F E p+u_{i}+\epsilon_{i t}
$$

where $y_{i t}$ stands for the various outcome variables pertaining to an individual $i$ (at round $t$ ) such as performance as captured by the number of right answers $(N R A)$, free-riding as proxied by the number of time-outs (NTIMEOUT), the occurrence of the sanction $(S A N C T=1)$ or the amount of the sanction $(M S A N C) . X$ is the vector of covariates other than the gender indicators such as the past period's sanction $\left(M S A N C_{-1}\right)$, the current and past, absolute and relative performance $\left(N R A_{-1}, D I F S C_{-1}\right.$ or DIFSC), round dummies, and various interaction terms with the female dummy $\left(F E \times M S A N C_{-1}\right.$, $F E \times D I F S C_{-1}$ or $\left.F E p \times D I F S C\right)$. The error term $u_{i}$ aims at capturing the individual random effect and $\epsilon_{i t}$ represents the standard error term.

It is important to note that when the interaction term is present, $\alpha_{1}$ can be interpreted as the impact of $F E$ (being a female subject) on $y$ when $F E p=0$ (having a men partner). Also, $\alpha_{2}$ can be interpreted as the impact of FEp (having a female partner) on $y$ when $F E=0$ (the subject is a men), which is tantamount to saying of the impact on $y$ of being a men with a female partner. More precisely, the marginal effect of being a women depends on whether she is teamed with a men or a women: $\frac{\partial y}{\partial F E}=\alpha_{1}+\alpha_{3} F E p$, and, the marginal effect of having a female partner depends on the subject is a female or a male: $\frac{\partial y}{\partial F E p}=\alpha_{2}+\alpha_{3} F E$. Note that the marginal effect of being a women who is paired 
with another woman is constant: $\frac{\partial^{2} y}{\partial F E \partial F E p}=\alpha_{3}$ (see Greene (1993) and Braumoeller (2004)).

The set of alpha coefficients also allows to grasp the impact of a team composition on the individual output variable. By definition of our gender indicator variables, the reference is the group of men who are paired with men [MM]. As already mentioned, $\alpha_{1}$ estimates the impact of being female who is paired with a male partner and $\alpha_{2}$ represents the impact of being male who is paired with a female partner. Thus the impact on individual output of being a woman teamed up with woman [W,W] is estimated by $\left(\alpha_{1}+\right.$ $\left.\alpha_{2}+\alpha_{3}\right)$.

\begin{tabular}{lll}
\hline Team Gender Composition & Dummy Values & Marginal Effects \\
\hline Men paired with men $[\mathrm{M}, \mathrm{M}]$ & $(\mathrm{FE}=0, \mathrm{FEp}=0)$ & Reference point \\
Women paired with men $[\mathrm{W}, \mathrm{M}]$ & $(\mathrm{FE}=1, \mathrm{FEp}=0)$ & $\alpha_{1}$ \\
Men paired with women $[\mathrm{M}, \mathrm{W}]$ & $(\mathrm{FE}=0, \mathrm{FEp}=1)$ & $\alpha_{2}$ \\
Women paired with women $[\mathrm{W}, \mathrm{W}]$ & $(\mathrm{FE}=1, \mathrm{FEp}=1)$ & $\left(\alpha_{1}+\alpha_{2}+\alpha_{3}\right)$ \\
\hline
\end{tabular}

\subsection{The performance regression model}

The first regression model aims at analyzing the determinants of performance. The dependent variable is the number of correct answers $(N R A)$ provided by an individual. Besides the gender indicator variables, a key explanatory variable is the past period's sanction $\left(M S A N C_{-1}\right)$. The number of correct answers in the previous round $\left(N R A_{-1}\right)$ is used as a control for the individual's ability in this task, including the net learning effect. Round dummies allow us to capture the residual learning/boredom effect (not captured by the coefficient on $N R A_{-1}$ ). Because we include one-period lagged variables, the dataset comprises only observations from round 2 to round 6 . It also excludes the two individuals who mis-specified their partners, which leaves 490 observations from five rounds for 98 individuals.

Table 6 presents the output of the panel data random-effects regression model. The model in column 1 does not include the interaction between being a female and receiving a sanction at the previous round, whereas this interaction is included in column 2 .

The impact of the group composition on the individual's performance can be gauged by the statistical significant coefficients of alphas in the first model:

\begin{tabular}{ll}
\hline Gender Composition & Marginal Effects \\
Women paired with men [W,M] & $\alpha_{1}=-0.878$ \\
Men paired with women [M,W] & $\alpha_{2}=-0.464$ \\
Women paired with women [W,W] & $\alpha_{1}+\alpha_{2}+\alpha_{3}=-0.378$ \\
\hline
\end{tabular}

Remark: $[\mathrm{M}, \mathrm{M}]$ groups as a reference point

Therefore, individual performance across teams follows the order of $[M, M]>[W, W]>$ $[M, W]>[W, M]$ (the gender order in the team stands for [subject, partner]).

Key findings are listed below:

R1. When a man is paired with a woman, his performance deteriorates compared to having a man partner, according to the negative coefficient on FEp, $\alpha_{2}=-0.464$.

R2. When a woman is paired with a man, her performance strongly deteriorates compared to having a women partner, according to the coefficient on $F E, \alpha_{1}=-0.878$.

We can turn now to the central theme of the analysis, the strategies and consequences of punishment. 
Table 6: Performance: the random-effects model

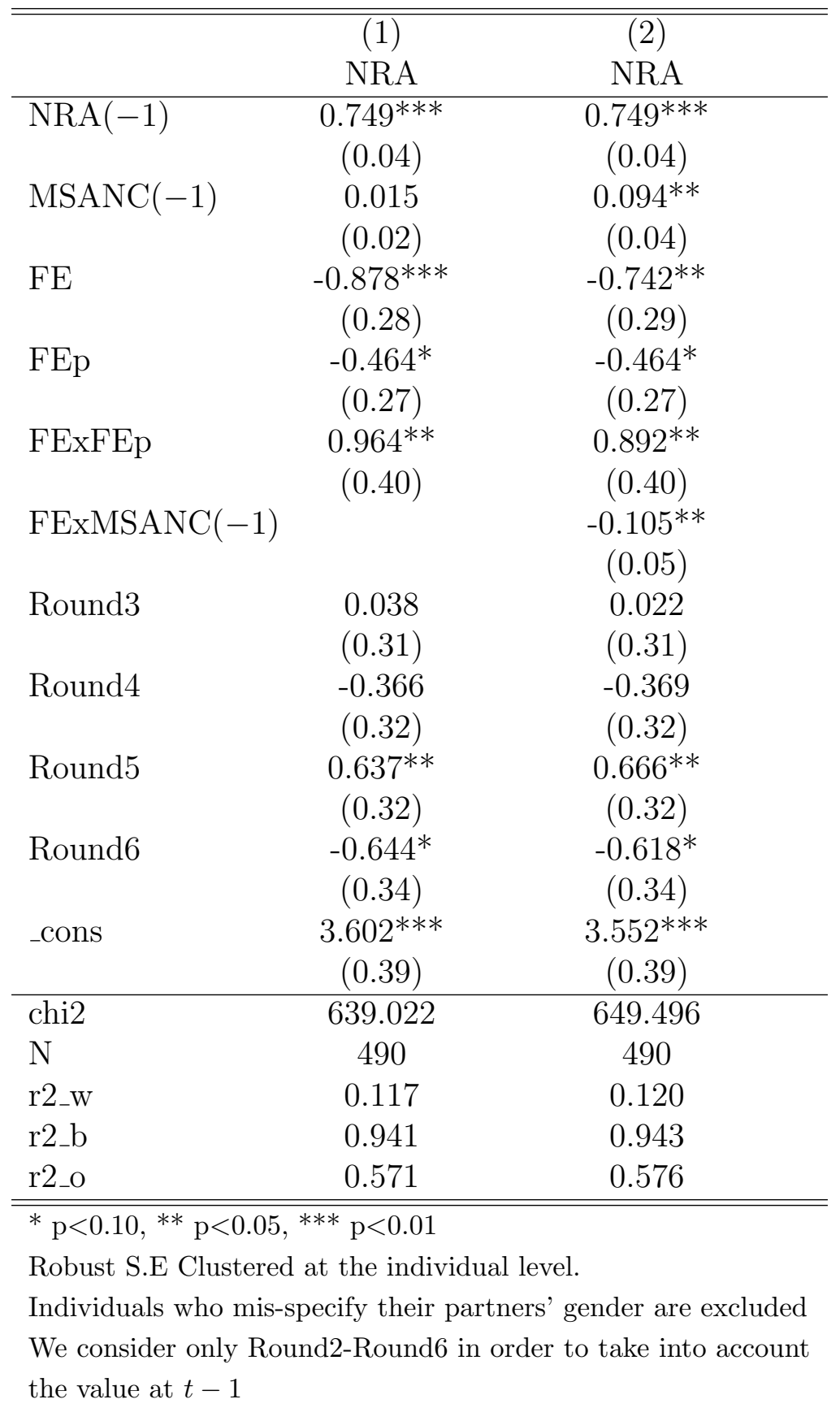


R3. On average, if a male subject was sanctioned in the previous round, he tends to perform better in the present round. The gain in performance is proportional to the amount of the sanction.

This can be inferred from the positive coefficient of $M S A N C_{-1},(0.094)$ which is statistically significant in model 2 . In presence of a significant interaction term $F E \times$ $M S A N C(-1)$, this coefficient on $M S A N C_{-1}$ indicates the marginal effect of the past sanction, conditional upon FE being zero (the subject is a man).

R4. However, if a woman was sanctioned at the previous round, her performance in the current round will not improve.

This is shown by the marginal effect of the sanction if the subject is a women, that is the sum of the coefficients of $M S A N C_{-1}$ and $F E \times M S A N C_{-1}$ in model 2 (i.e. $0.094+$ $(-0.105) \approx 0)$.

It appears that the motivation crowding-out effect mainly affects female subjects, a result in line with findings by Rask and Tiefenthaler (2008).

R5. Performance improves across rounds, but conditionally on individual abilities, the round effects are rather mixed.

Finally, we also assessed whether an excessive sanction might entail a motivation crowding-out effect by including a quadratic term of the $M S A N C$ variable in the above mentioned regression models. Its coefficient is negative, which would suggest support for the motivation crowding-out theory, but it is not statistically significant.

\subsection{Determinants of the free-riding behavior}

As we have emphasized, the number of times that subjects pressed the time-out button provides a indication of their propensity to free ride (and take the risk of being sanctioned). On average men press the button more often than women. As NTIMEOUT and NRA are negatively correlated, one could imagine that the motivational factors determining free riding can be explained similarly to those driving performance. We therefore estimate the same type of regression model as in the previous section, but here use NTIMEOUT as the dependent variable. The sample includes the same 490 observations. Table 7 reports results of the random-effects panel data regression.

The coefficients of alphas in the first model is given as follows:

\begin{tabular}{ll}
\hline Gender Composition & Marginal Effects \\
Women paired with men [W,M] & $\alpha_{1}=0.210$ \\
Men paired with women [M,W] & $\alpha_{2}=0.531$ \\
Women paired with women [W,W] & $\alpha_{1}+\alpha_{2}+\alpha_{3}=-0.168$ \\
\hline
\end{tabular}

Remark: $[\mathrm{M}, \mathrm{M}]$ groups as a reference point

Therefore subject free-riding across teams [subject, partner] follows the order $[M, W]>$ $[W, M]>[M, M]>[W, W]$.

We can note that:

R6. Better-performing individuals tend to free-ride (press the time-out button) less often.

This is indicated by the negative and statistically significant coefficient of $N R A_{-1}$.

R7. Controlling for individual ability, on average subjects tend to free-ride (press the time-out button) more often when paired with the opposite gender. Individuals in mixed teams tend to free ride more than individuals in same gender teams. 
Table 7: Determinant of Free-Riding (The Number of Times the Time-Out Button was Pressed): the random-effects model

\begin{tabular}{|c|c|c|c|c|}
\hline & $\begin{array}{c}(1) \\
\text { NTIMEOUT }\end{array}$ & $\begin{array}{c}(2) \\
\text { NTIMEOUT }\end{array}$ & $\begin{array}{c}(3) \\
\text { NTIMEOUT }\end{array}$ & $\begin{array}{c}(4) \\
\text { NTIMEOUT }\end{array}$ \\
\hline $\operatorname{NRA}(-1)$ & $\begin{array}{c}-0.094^{* * *} \\
(0.03)\end{array}$ & $\begin{array}{c}-0.094^{* * *} \\
(0.03)\end{array}$ & $\begin{array}{c}-0.097^{* * *} \\
(0.03)\end{array}$ & $\begin{array}{c}-0.097^{* * *} \\
(0.03)\end{array}$ \\
\hline $\operatorname{MSANC}(-1)$ & $\begin{array}{l}-0.013 \\
(0.01)\end{array}$ & $\begin{array}{l}-0.040 \\
(0.03)\end{array}$ & $\begin{array}{r}-0.011 \\
(0.01)\end{array}$ & $\begin{array}{l}-0.041 \\
(0.03)\end{array}$ \\
\hline $\mathrm{FE}$ & $\begin{array}{l}0.210 \\
(0.20)\end{array}$ & $\begin{array}{l}0.153 \\
(0.20)\end{array}$ & $\begin{array}{l}0.224 \\
(0.20)\end{array}$ & $\begin{array}{l}0.167 \\
(0.20)\end{array}$ \\
\hline FEp & $\begin{array}{c}0.531^{* * *} \\
(0.19)\end{array}$ & $\begin{array}{c}0.535^{* * *} \\
(0.19)\end{array}$ & $\begin{array}{c}0.528^{* * *} \\
(0.19)\end{array}$ & $\begin{array}{c}0.532^{* * *} \\
(0.19)\end{array}$ \\
\hline FExFEp & $\begin{array}{c}-0.909^{* * *} \\
(0.28)\end{array}$ & $\begin{array}{c}-0.883^{* * *} \\
(0.28)\end{array}$ & $\begin{array}{c}-0.920^{* * *} \\
(0.28)\end{array}$ & $\begin{array}{c}-0.894^{* * *} \\
(0.28)\end{array}$ \\
\hline FExMSANC $(-1)$ & & $\begin{array}{r}0.037 \\
(0.03)\end{array}$ & & $\begin{array}{l}0.039 \\
(0.03)\end{array}$ \\
\hline FExDIFSC $(-1)$ & & & $\begin{array}{l}0.016 \\
(0.03)\end{array}$ & $\begin{array}{l}0.019 \\
(0.03)\end{array}$ \\
\hline Round3 & $\begin{array}{l}-0.039 \\
(0.21)\end{array}$ & $\begin{array}{c}-0.034 \\
(0.21)\end{array}$ & $\begin{array}{l}-0.035 \\
(0.21)\end{array}$ & $\begin{array}{l}-0.029 \\
(0.21)\end{array}$ \\
\hline Round4 & $\begin{array}{c}0.480^{* *} \\
(0.22)\end{array}$ & $\begin{array}{c}0.481^{* *} \\
(0.22)\end{array}$ & $\begin{array}{c}0.486^{* *} \\
(0.22)\end{array}$ & $\begin{array}{c}0.488^{* *} \\
(0.22)\end{array}$ \\
\hline Round5 & $\begin{array}{c}0.407^{*} \\
(0.22)\end{array}$ & $\begin{array}{c}0.396^{*} \\
(0.22)\end{array}$ & $\begin{array}{c}0.416^{*} \\
(0.22)\end{array}$ & $\begin{array}{c}0.407^{*} \\
(0.22)\end{array}$ \\
\hline Round6 & $\begin{array}{c}0.521^{* *} \\
(0.23)\end{array}$ & $\begin{array}{c}0.512^{* *} \\
(0.23)\end{array}$ & $\begin{array}{c}0.535^{* *} \\
(0.24)\end{array}$ & $\begin{array}{c}0.527^{* *} \\
(0.24)\end{array}$ \\
\hline _cons & $\begin{array}{c}1.175^{* * *} \\
(0.28)\end{array}$ & $\begin{array}{c}1.196^{* * *} \\
(0.28)\end{array}$ & $\begin{array}{c}1.197^{* * *} \\
(0.29)\end{array}$ & $\begin{array}{c}1.223^{* * *} \\
(0.29)\end{array}$ \\
\hline chi2 & 36.664 & 38.201 & 36.903 & 38.557 \\
\hline $\mathrm{N}$ & 490 & 490 & 490 & 490 \\
\hline $\mathrm{r} 2 \_\mathrm{w}$ & 0.078 & 0.082 & 0.078 & 0.083 \\
\hline r2_b & 0.006 & 0.001 & 0.004 & 0.000 \\
\hline r2_o & 0.065 & 0.066 & 0.066 & 0.068 \\
\hline $\begin{array}{l}* \mathrm{p}<0.10,{ }^{* *} \mathrm{p}<0.05 \\
\text { Robust S.E Clustered } \\
\text { Individuals who mis- } \\
\text { We consider only Ro } \\
\text { the value at } t-1\end{array}$ & $\begin{array}{l}* * * \mathrm{p}<0.01 \\
\text { at the individual } \\
\text { pecify their partne } \\
\text { nd2-Round6 in or }\end{array}$ & $\begin{array}{l}\text { level. } \\
\text { rs' gender are ex } \\
\text { ler to take into a }\end{array}$ & $\begin{array}{l}\text { uded } \\
\text { count }\end{array}$ & \\
\hline
\end{tabular}


R8. If a man is paired with a woman, he free-rides more often than when paired with a man, according to the positive coefficient on FEp.

R9. If a women is paired with a men, she free-rides more often than when paired with a women, according to the comparison of the positive (or insignificant) $\alpha_{1}$ and the negative $\left(\alpha_{1}+\alpha_{2}+\alpha_{3}\right)$.

R10. Over time, boredom or fatigue prompts participants to press the time-out button more often.

All coefficients for rounds 4 to 6 are positive and statistically significant.

\subsection{The sanction regression model}

We can turn now our attention to the determinants of sanctioning behavior. To do so, we estimate several regression models, using as a dependent variable either the indicator variable $S A N C$ (1 if a sanction is imposed) or the ECU amount of the sanction, $M S A N C$. There were initially 275 observations for which the sanction option was available (i.e., the subject performed better than his/her partner); however, five observations from the two individuals who mis-specified their partners must be excluded. As there are six rounds, we can treat this dataset as panel data, thereby allowing us to use a random-effects model to control for both individuals and time effects. As dependent variables we use the same gender indicator variables as in the performance equation ( $F E, F E p$ and their interaction), to which we add the difference in scores between the two partners (DIFSC) and the interaction term $F E p \times D I F S C$. Given that we control now for the difference in performance (on average men tend to have a better performance in this task), the indicator variables would capture the "plain" gender effect.

Table 8 reports the estimation output. We use three different specifications for both $S A N C$ and $M S A N C$; columns (1) and (4) present the regression model without interaction terms, columns (2) and (5) include the $F E \times F E p$ interaction term, and columns (3) and (6) include the FEp $\times D I F S C$ interaction term.

This brings us to:

R11. The frequency of imposing sanctions and the amount of the sanction is positively related to the difference in the number of correct answers (performance). In other words, the worse the relative performance of the poor performer on the team is, the higher will be his/her sanction (or likelihood of receiving a sanction).

This is shown by the positive and significant coefficient on DIFSC in models (1), (2), and (4).

R12. When women perform poorly, they tend to be penalized significantly more than men.

This is reflected by the positive coefficient of FEp (strongly significant in models (1), (2), (4)).

R13. The sanction response to poor performance is stronger when the poor performer on the team is a woman

Indeed, the coefficients of the interaction term between FEp (the partner is a woman) and DIFSC (the difference in performance between team members) is significantly positive.

R14. Women tend to sanction less (not significant).

This is shown by the negative coefficient of $F E$, albeit this result is not statistically significant.

R15. The frequency and magnitude of sanctioning is the highest in the second round. 
Table 8: Sanction Determinants: the random-effects model

\begin{tabular}{|c|c|c|c|c|c|c|}
\hline & $\begin{array}{c}(1) \\
\text { SANC }\end{array}$ & $\begin{array}{c}(2) \\
\text { SANC }\end{array}$ & $\begin{array}{c}(3) \\
\text { s }\end{array}$ & $\begin{array}{c}(4) \\
M S A N C\end{array}$ & $\begin{array}{c}(5) \\
M S A N C\end{array}$ & $\begin{array}{c}(6) \\
M S A N C\end{array}$ \\
\hline \multirow[t]{2}{*}{ DIFSC } & $0.041^{* * *}$ & $0.037^{* * *}$ & $0.018^{*}$ & $0.876^{* * *}$ & $0.865^{* * *}$ & 0.270 \\
\hline & $(0.01)$ & $(0.01)$ & $(0.01)$ & $(0.18)$ & $(0.18)$ & $(0.22)$ \\
\hline \multirow[t]{2}{*}{$\mathrm{FE}$} & -0.056 & -0.034 & -0.049 & -1.148 & -0.256 & -0.877 \\
\hline & $(0.05)$ & $(0.08)$ & $(0.05)$ & $(0.91)$ & $(1.42)$ & $(0.88)$ \\
\hline \multirow[t]{2}{*}{ FEp } & $0.210^{* * *}$ & $0.222^{* * *}$ & $0.042^{*}$ & $3.894^{* * *}$ & $4.386^{* * *}$ & -1.022 \\
\hline & $(0.05)$ & $(0.06)$ & $(0.08)$ & $(0.91)$ & (1.11) & $(1.42)$ \\
\hline \multirow[t]{2}{*}{ FExFEp } & & -0.067 & & & -1.652 & \\
\hline & & $(0.10)$ & & & $(1.81)$ & \\
\hline \multirow[t]{2}{*}{ FEpxDIFSC } & & & $0.049^{* * *}$ & & & $1.416^{* * *}$ \\
\hline & & & $(0.02)$ & & & $(0.33)$ \\
\hline \multirow[t]{2}{*}{ Round2 } & $0.147^{* *}$ & $0.140^{*}$ & $0.140^{*}$ & $2.990 * *$ & $2.909 * *$ & $2.765^{* *}$ \\
\hline & $(0.07)$ & $(0.08)$ & $(0.07)$ & $(1.36)$ & $(1.39)$ & $(1.36)$ \\
\hline \multirow[t]{2}{*}{ Round3 } & 0.048 & 0.039 & 0.054 & 1.665 & 1.625 & 1.865 \\
\hline & $(0.07)$ & $(0.08)$ & $(0.07)$ & $(1.34)$ & $(1.37)$ & $(1.34)$ \\
\hline \multirow[t]{2}{*}{ Round4 } & 0.082 & 0.062 & 0.061 & 1.943 & 1.890 & 1.447 \\
\hline & $(0.07)$ & $(0.08)$ & $(0.07)$ & (1.37) & $(1.39)$ & $(1.36)$ \\
\hline \multirow[t]{2}{*}{ Round5 } & -0.046 & -0.055 & -0.053 & 0.868 & 0.844 & 0.731 \\
\hline & $(0.07)$ & $(0.08)$ & $(0.07)$ & $(1.36)$ & (1.39) & $(1.36)$ \\
\hline \multirow[t]{2}{*}{ Round6 } & -0.011 & -0.025 & -0.019 & $2.255^{*}$ & 2.145 & 2.033 \\
\hline & $(0.07)$ & $(0.08)$ & $(0.07)$ & $(1.37)$ & (1.39) & $(1.36)$ \\
\hline \multirow[t]{2}{*}{ _cons } & -0.074 & -0.047 & 0.010 & $-3.397^{* *}$ & $-3.484^{* *}$ & -1.131 \\
\hline & $(0.07)$ & $(0.07)$ & $(0.08)$ & (1.39) & $(1.37)$ & (1.39) \\
\hline chi2 & 45.906 & 42.760 & 52.899 & 51.113 & 51.989 & 72.504 \\
\hline $\mathrm{N}$ & 270 & 270 & 270 & 270 & 270 & 270 \\
\hline $\mathrm{r} 2 \_\mathrm{w}$ & 0.158 & 0.148 & 0.169 & 0.157 & 0.155 & 0.189 \\
\hline r2_b & 0.171 & 0.216 & 0.272 & 0.255 & 0.294 & 0.437 \\
\hline r2_o & 0.131 & 0.136 & 0.157 & 0.156 & 0.164 & 0.220 \\
\hline
\end{tabular}

${ }^{*} \mathrm{p}<0.10,{ }^{* *} \mathrm{p}<0.05,{ }^{* * *} \mathrm{p}<0.01$, Robust S.E Clustered at the individual level.

5 observations from Individuals who mis-specify their partners' gender are excluded 
Table 9: Preference Questionnaire about Partner/Gender

\begin{tabular}{lccc}
\hline \hline & $(1)$ & $(2)$ & $(3)$ \\
& Performance Partner & Performance Other Gender & Punishment Other Gender \\
\hline FE & -0.227 & 0.042 & -0.233 \\
& $(0.23)$ & $(0.21)$ & $(0.30)$ \\
FEp & -0.283 & 0.220 & $0.440^{* *}$ \\
& $(0.26)$ & $(0.19)$ & $(0.20)$ \\
FExFEp & 0.488 & -0.261 & 0.493 \\
& $(0.34)$ & $(0.25)$ & $(0.33)$ \\
FEpxAvDIFSC & -0.109 & -0.038 & $-0.139^{* * *}$ \\
& $(0.07)$ & $(0.05)$ & $(0.05)$ \\
AvDIFSC & $-0.181^{* * *}$ & 0.059 & $0.056^{*}$ \\
& $(0.05)$ & $(0.04)$ & $(0.03)$ \\
_cons & $3.906^{* * *}$ & $3.000^{* * *}$ & $3.031^{* * *}$ \\
& $(0.14)$ & $(0.15)$ & $(0.15)$ \\
\hline $\mathrm{N}$ & 98 & 98 & 98 \\
$\mathrm{r} 2$ & 0.474 & 0.083 & 0.245 \\
\hline \hline
\end{tabular}

$* \mathrm{p}<0.10,{ }^{* *} \mathrm{p}<0.05, * * * \mathrm{p}<0.01$

Bootstrapping 1000 replications

2 Individuals who mis-specify their partners' gender are excluded.

avDIFSC is the average of DIFSC for each individual.

The second round coefficients are positive and statistically significant in all models. After the second round, round effects appear to disappear.

\subsection{The perception regression model.}

As noted above, at the end of the experimental session participants were asked to answer three questions regarding their gender preference and use a five-item scale to rank their answers (from very good to very poor). The sample includes the 98 participants who knew the gender of their partner. Table 9 presents the regression models using these expressed preferences as a dependent variable. The AvDIFSC is the all-round average difference in an individual's score (positive if he/she outperformed, negative if he/she under-performed), and $F E p \times A v D I F S C$ is the interaction term with the partner being female.

The first column presents the results for the question "How do you evaluate your partner's performance?". While many factors are insignificant, we find that:

$\mathbf{R} 16$. The better the relative performance of an individual, the lower the assessment of his/her partner's performance (and vice-versa).

In line with intuition, this result is confirmed by the negative coefficient of AvDIFSC.

R17. However, all things equal, subjects tend to be more critical of women than of men, by under-estimating the ex-post performance of women.

This is reflected by the statistically significant negative coefficient of the interaction term FEp $\times A v D I F S C$.

The second column pertains to the question "In this experiment, considering the performance of your partner, you believe that a [opposite gender as partner] would have performed" for which we did not observe any significant results. Based solely on the sign of coefficient of $F E p$, if the subject was paired with a woman, s/he tended to believe that 
if $\mathrm{s} /$ he had been paired with a man, the male partner would have performed better (and this belief is stronger for men, as shown by the sign of $F E \times F E p)$. This suggests that subjects naturally underestimate the performance of women.

The final column reports the results for the question "If your partner had been of the opposite gender, how do you imagine s/he would have penalized you?".

R18. As shown by the positive and significant coefficient of FEp, if a male had been paired with a female, he believes that if the partner had been a man, he would have imposed heavier sanctions.

Subjects naturally tended to believe that women would penalize less than men, which is in line with the observed behavior in this experiment.

These answers suggest that negative gender stereotypes in the workplace still exists, and they affect not only the men but also women themselves.

\section{Conclusion}

Gender discrimination in the workplace is an important research subject, which is motivated by the still worrisome situation of women in many enterprises and work environments (Azmat and Petrongolo (2014)). The aim of this paper is to contribute to this literature by developing a real-effort experiment in which pairs of individuals were asked to "produce" correct answers in a counting task. In the experiment, subjects must count $7 \mathrm{~s}$ in blocs of figures displayed successively on the computer screen (Mohnen et al. (2008), Pokorny (2008), Vranceanu et al. (2014)). Partners on a team receive an equal share of the team's output as compensation. Furthermore, the best performer on a team is given the option to impose a monetary sanction on the less-effective partner. As an original contribution, in this paper we manipulate the gender composition of the teams, and observe individual behavior in all-men, all-women and mixed teams.

Among the main results, we emphasize the following:

(1) On average, in this task men perform slightly better than women;

(2) Men's individual performance is the strongest when paired with another man, and will deteriorate when paired with women;

(3) Women paired with women will have a strong individual performance, but their performance will deteriorate when paired with men;

(4) When underperforming, all other things equal, women are sanctioned more often and more heavily than men;

(5) If sanctioned, women's performance will not improve, whereas men tend to improve their performance.

Compared to other real-effort tasks used in team production experiments (such as coding and solving mazes), this task does not require any particular reasoning skills, but draws heavily on attention, focus and resistance to boredom. One might argue that according to "die-hard" stereotypes, "counting" is a task where men are expected to do better than women, which would bias the results. While it seems hard to sustain such a belief in our population of students recruited through a tough national competitive exam (including maths), it would be interesting to study in future research whether the main results hold if participants are required to perform a different task. Also, our results, observed in two-person teams, might be less prominent in larger groups, in particular since the incentive to free-ride on the punishment would be stronger. Finally, as for all experiments, extreme caution is required when trying to extrapolate conclusions from such a simple experiment to real life situations. 
With these caveats, our analysis can shed some light on the dynamics of performance in teams. We observed that men tended to improve their performance from one round to another when they were sanctioned, and the gain in performance was positively related to the amount of the sanction. Thus, in all-men teams, internal punishment should contribute to improve the team's performance. Furthermore, as the sanction is proportional to the difference in scores, in the long run, the gap in the performance of the two team members should narrow to the lowest natural difference in abilities, with sanctions gradually declining and stabilizing. However, we have shown that women do not respond to sanctions by improving their performance (it might even slightly decrease). Furthermore, should they under-perform, they receive larger sanctions than men, and these sanctions are the most substantial when women are paired with men. Thus, in mixed teams where man outperform his women team-mate, punishment might be counterproductive, by deteriorating motivation and reducing efforts.

In many enterprises and organizations, production was historically primarily completed by men. This is true for many mass-production processes in manufacturing and construction, but also in many clerical jobs (consulting, law firms, and even in academia). It is easy to understand why a norm of punishing defectors should emerge in such work environments. With the accelerated feminization of many organizations, the gender composition of teams is changing rapidly. Yet, if norms do not change at the same pace, and workers uniformly impose internal punishment, firms' performances might well stagnate. At one moment it might be useful to rediscover the value of forgiveness.

\section{Acknowledgments}

This project was carried out within the research framework of the Labex MME-DII (http://labex-mme-dii.u-cergy.fr). The authors would like to thank the ESSEC Research Center for having funded this research and to Delphine Dubart from the ESSEC Experimental Lab for her technical assistance. They would like to thank participants to the ESSEC Behavioral Workshop on March 2015 in Cergy, to the THEMA Research Seminar on April 2015 in Cergy, to the Annual Conference of the French Association of Experimental Economics (ASFEE), 14-15 June 2015, Paris, to the Research Workshop of the GATE, Lyon, on June 19th 2015, and to Agnieszka Wysokina and Maia Linask for their suggestions and remarks on an early draft.

\section{References}

Alchian, A. A. And H. Demsetz, "Production, Information Costs, and Economic Organization," American Economic Review 62 (December 1972), 777-95.

Apesteguia, J., G. Azmat and N. Iriberri, "The Impact of Gender Composition on Team Performance and Decision Making: Evidence from the Field," Management Science 58 (January 2012), 78-93.

Azmat, G. And B. Petrongolo, "Gender and the labor market: What have we learned from field and lab experiments?," Labour Economics 30 (2014), 32-40.

Barron, J. M., Gjerde And K. Paulson, "Peer Pressure in an Agency Relationship," Journal of Labor Economics 15 (April 1997), 234-54. 
Ben-Ner, A., F. Kong And L. Putterman, "Share and Share Alike? Gender-pairing, Personality, and Cognitive Ability as Determinants of Giving," Journal of Economic Psychology 25 (October 2004), 581-589.

Benndorf, V., H. A. RAU And C. Sölch, "Minimizing Learning Behavior in Experiments with Repeated Real-Effort Tasks," Available at SSRN: http://ssrn.com/abstract=2503029 or http://dx.doi.org/10.2139/ssrn.2503029 (2014).

Boning, B., C. IChniowski And K. Shaw, "Opportunity Counts: Teams and the Effectiveness of Production Incentives," Journal of Labor Economics 25(4) (2007), 61350 .

Braumoeller, B. F., "Hypothesis Testing and Multiplicative Interaction Terms," International Organization 58 (10 2004), 807-820.

Buss, D., Evolutionary Psychology: The New Science of the Mind (Boston, Allyn and Bacon., 1998).

Camerer, C. F. And E. Fehr, "When does "Economic Man" Dominate Social Behavior?," Science 311(5757) (2006), 47-52.

Campbell, A., "Staying Alive: Evolution, Culture, and Women's Intrasexual Aggression," Behavioral and Brain Sciences 22 (1999), 203-252.

Che, Y.-K. And S.-W. Yoo, "Optimal Incentives for Teams," American Economic Review 91 (June 2001), 525-541.

Croson, R. And U. Gneezy, "Gender Differences in Preferences," Journal of Economic Literature 47(2) (2009), 1-27.

Dickinson, D. And M.-C. Villeval, "Does Monitoring Decrease Work Effort? The Complementarity Between Agency and Crowding-Out Theories," Games and Economic Behavrior 63 (2008), 56-76.

Dufwenberg, M. And A. Muren, "Generosity, Anonymity, Gender," Journal of Economic Behavior and Organization 61(1) (2006), 42-49.

Eckel, C. C. And S. C. Füllbrunn, "Thar SHE Blows? Gender, Competition, and Bubbles in Experimental Asset Markets," American Economic Review 105 (2015), 90620 .

Eckel, C. C. and P. J. Grossman, "Chivalry and Solidarity in Ultimatum Games," Economic Inquiry 39 (2001), 171-188.

, "Differences in the Economic Decisions of Men and Women: Experimental Evidence," Handbook of Experimental Economics Results 1(57) (2008), 509-519.

Falk, E. F., Armin and U. Fischbacher, "Driving Forces behind Informal Sanctions," Econometrica 73(6) (2005), 2017-2030.

Fehr, E. And S. Gächter, "Cooperation and Punishment in Public Goods Experiments," American Economic Review 90(4) (2000), 980-994. 
FeHR, E. AND J. List, "The Hidden Costs and Returns of Incentives - Trust and Trustworthiness among CEOs," Journal of the European Econonmic Association 2 (2004), $743-771$.

Fehr, E. AND B. Rockenbach, "Detrimental Effects of Sanctions on Human Altruism," Nature 422 (2003), 137-140.

Fershtman, C. And U. Gneezy, "Discrimination In A Segmented Society: An Experimental Approach," The Quarterly Journal of Economics 116 (February 2001), 351-377.

Festré, A. And P. Garrouste, "Theory and Evidence in Psychology and Economics about Motivation Crowding Out: A Possible Convergence?," Journal of Economic Surveys, On-line in-print, http://dx.doi.org/10.1111/joes.12059 (2014).

Filippin, A. And P. Crosetto, "A Reconsideration of Gender Differences in Risk Attitudes," IZA Discussion Papers 8184, Institute for the Study of Labor (IZA), May 2014.

FischBACHER, U., "z-Tree: Zurich Toolbox for Ready-made Economic Experiments," Experimental Economics 10 (June 2007), 171-178.

Frey, B. S. And R. Jegen, "Motivation Crowding Theory," Journal of Economic Surveys 15(5) (2001), 589-611.

Gneezy, U., "The W Effect of Incentives," Levine's Bibliography 666156000000000315, UCLA Department of Economics, October 2003.

Greene, W. H., Econometric Analysis (Prentice Hall, New Jersey, 1993).

Holmstrom, B., "Moral Hazard in Teams," Bell Journal of Economics 13 (Autumn 1982), 324-340.

Hoogendoorn, S., H. Oosterbeek and M. V. PraAg, "The Impact of Gender Diversity on the Performance of Business Teams: Evidence from a Field Experiment," Management Science 59(7) (2013), 1514-1528.

Houser, D., E. Xiao, K. McCabe And V. Smith, "When Punishment Fails: Research on Sanctions, Intentions and Non-cooperation," Games and Economic Behavior 62 (March 2008), 509-532.

Iтон, H., "Incentives to Help in Multi-agent Situations," Econometrica 59 (May 1991), 611-36.

Kanazawa, S., "Is "Discrimination" Necessary to Explain the Sex Gap in Earnings?," Journal of Economic Psychology 26(2) (2005), 269-287.

Kandel, E. And E. P. Lazear, "Peer Pressure and Partnerships," Journal of Political Economy 100(4) (1992), 801-817.

Kirstein, A., "Bonus and Malus in Principal Agent Relations with Fixed Pay and Real Effort," Fixed Wage 60 (2008), 280-303.

Kuhn, P. And M.-C. Villeval, "Are Women More Attracted to Co-operation Than Men?," Economic Journal 125 (2013), 115-140. 
Lamiraud, K. and R. Vranceanu, "Group Gender Composition, Tolerance to Risk and Economic Performance: New Evidence from an Original Business Game," mimeo, ESSEC. (2014).

Lawler, E. E. I. And S. A. Mohrman, "Pay Practices in Fortune 1000 Corporations," Center for Effective Organizations, publication G 448 (2003), 3-20.

Legros, P. And S. A. Matthews, "Efficient and Nearly-Efficient Partnerships," Review of Economic Studies 60 (July 1993), 599-611.

McAfee, R. P. And J. McMillan, "Optimal Contracts for Teams," International Economic Review 32 (August 1991), 561-77.

Mohnen, A., K. Pokorny And D. SliwkA, "Transparency, Inequity Aversion, and the Dynamics of Peer Pressure in Teams: Theory and Evidence," Journal of Labor Economics 26 (October 2008), 693-720.

Niederle, M. And L. Vesterlund, "Do Women Shy Away from Competition? Do Men Compete Too Much?," Quarterly Journal of Economics 122 (08 2007), 1067-1101.

—_, "Gender and Competition," Annual Review in Economics 3 (2011), 601-630.

Nikiforakis, N. And H.-T. Normann, "A Comparative Statics Analysis of Punishment in Public-good Experiments," Experimental Economics 11 (December 2008), 358-369.

Ortmann, A. And L. K. Tichy, "Gender Differences in the Laboratory: Evidence from Prisoner's Dilemma Games," Journal of Economic Behavior and Organization 39 (July 1999), 327-339.

Pokorny, K., "Pay-But Do Not Pay Too Much: An Experimental Study on the Impact of Incentives," Journal of Economic Behavior and Organization 66 (May 2008), 251264.

Rask, K. And J. Tiefenthaler, "The role of grade sensitivity in explaining the gender imbalance in undergraduate economics." Economics of Education Review 27 (2008), 676-687.

Solnick, S. J., "Gender differences in the ultimatum game.," Economic Inquiry 39(2) (2001), 189-200.

Tajfel, H., Human Groups and Social Categories (Cambridge University Press, 1981).

Vranceanu, R., F. E. Ouardighi and D. Dubart, "Team Production with Punishment Option: Insights from a Real-Effort Experiment," Managerial and Decision Economics Online at: http://dx.doi.org/10.1002/mde.2678. (2014). 


\section{APPENDIX}

\section{DESCRIPTION OF VARIABLES}

FE Indicator variable: [1] if the subject is female, [0] if else.

FEp Indicator variable: [1] if the subject is paired with a woman, [0] if else.

NRA The number of correct answers provided by the individual.

$\operatorname{NRA}(-1)$ The number of correct answers provided by the individual in the previous round.

NBLOCK Number of blocks counted by the subject during the round

NTIMEOUT Number of times that the time-out button was pressed by the subject during the round

DIFSC The difference between the number of correct responses of subject $i$ and that of his/her partner $j: N R A_{i}-N R A_{j}$ in the current round

AvDIFSC The average of DIFSC over the 6 rounds for an individual

SANC Dummy variable: [1] if the subject penalizes his/her partner conditional on the subject performing better than his/her partner.

MSANC The amount of penalty that the subject imposes on his/her partner when the former performs better than his/her partner.

MSANC $(-1)$ The amount of sanction imposed by the partner at the previous round when an individual performed worse than the partner.

FExMSANC $(-1)$ The interaction term between $M S A N C_{-1}$ and $F E$.

FExDIFSC $(-1)$ The interaction term between $D I F S C_{-1}$ and $F E$.

FEpxDIFSC The interaction between DIFSC and FEp.

FEpxAvDIFSC The interaction term between FEp and AvDIFSC.

Round\# Dummies for each round. 


\section{INSTRUCTIONS ${ }^{12}$}

\section{Slide 1.}

Good morning. Thank you for participating in this experiment. Please read these instructions carefully and, should you have any questions, raise your hand and call the administrator. Communication between participants is forbidden. Please turn off cellular phones. A payment in cash will be provided at the end of the session.

\section{Slide 2. Personal characteristics}

-You are: [A man / A woman]

-Your age is $[\mathrm{X}]$

-Your education level is: [Baccalaureate $+1,+2,+3,+4+5,+6$ or more years of education]

\section{Slide 3. About your partner}

In this experiment you will be paired at random with another person present in this room; this pairing is strictly anonymous.

-The gender of the partner is: [man/women]

-The age of the partner is: $[\mathrm{X}]$

-The education level of the partner is: [Baccalaureate $+1,+2,+3,+4+5,+6$ or more years of education]

\section{Slide 4. Main rule}

-You will be required to perform an effort task jointly with a partner, during 4 identical rounds of the same experiment.

-Each round lasts for 4 minutes; the clock starts when you open the first active screen, and stops after 4 minutes. During a round, the remaining time is displayed in red characters, in the upper right corner of the screen (in seconds).

-A payoff in euros will be delivered at the end of the experiment. The payment is connected to performance in the task, according to a rule known to everyone.

-Partners will be matched in pairs at random. Your partner will not change from one round to another. His identity will not be revealed to you.

-During each round the computer displays a sequence of blocs of figures (0 to 9) in six lines and 30 columns. Your task is to accurately count how many times the figure 7 appears in a bloc and then report this number in a box. The answer is considered correct if it corresponds to the right number of $7 \mathrm{~s}$ in the bloc, with a tolerated error margin of 1 . For instance, if the correct number of $7 \mathrm{~s}$ is 30 , answers 29, 30 and 31 will be considered correct.

-Once the counted number of $7 \mathrm{~s}$ is recorded in the box, you must press the "validate" button, to save it. After you click, a new random block of figures is automatically generated and the effort task can continue.

-At any moment you can take a break by pressing the button "Take a break". The break stops the counting task for 20 seconds; a screen with ESSEC logo appears. If the round stops in less than 20 seconds, breaks are no longer possible.

-At the end of each round the computer will display the total number of correct answers that you have provided and the total number of correct answers provided by your partner. -At the end of each round, before moving to the next round, the player who provided the highest number of correct answers can, if he/she wants so, impose a fine on his/her part-

\footnotetext{
${ }^{12}$ Translated from French.
} 
ner. The decision belongs to him/her, it is not compulsory to impose the fine. In the event that players have provided an identical number of correct answers, no sanction is possible.

\section{Slide 5. The example slide - main decision screen}

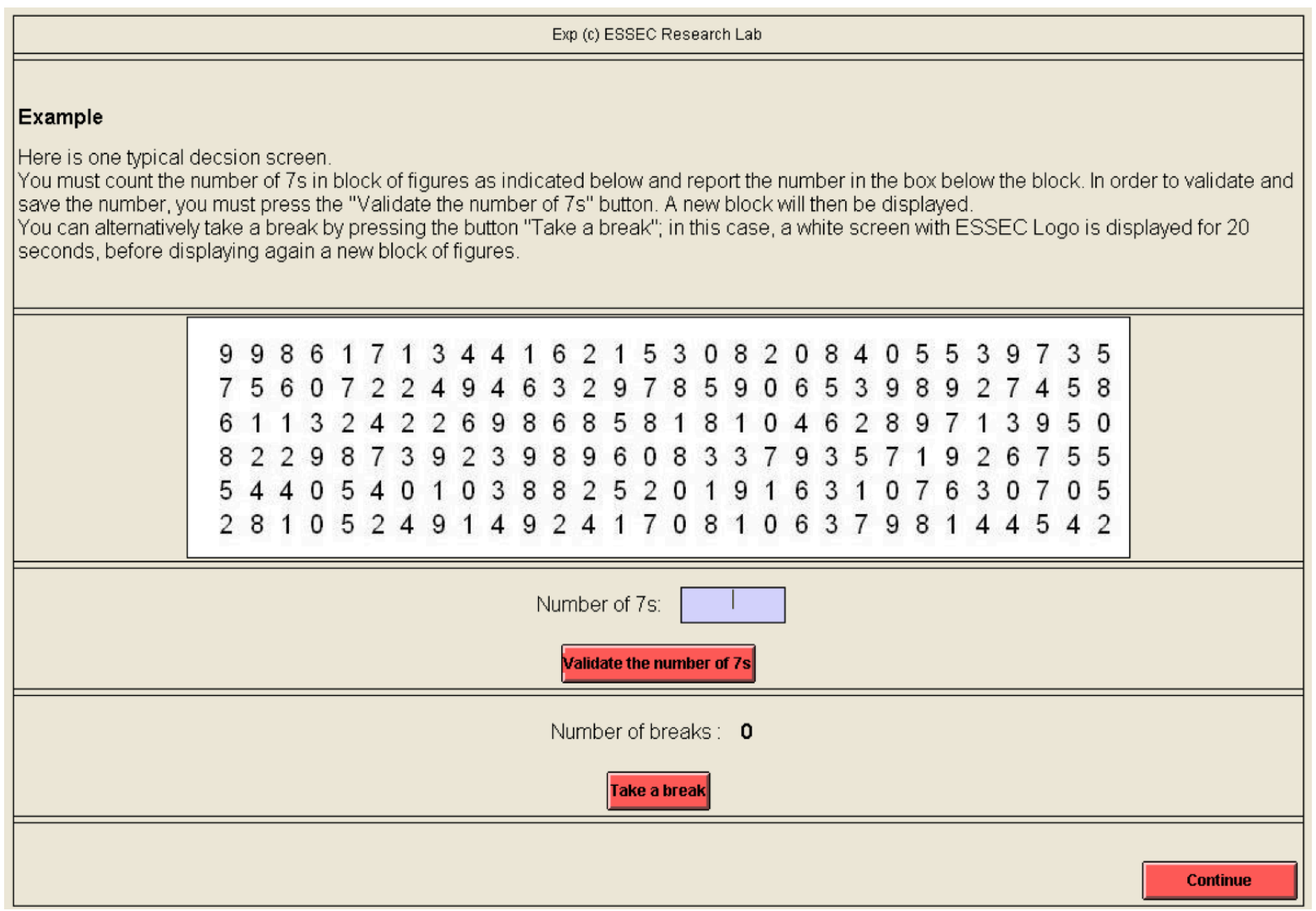

\section{Slide 6. Compensation rule}

Gains are denominated in Experimental Currency Units (ECU). For each round, the payoff for one player is made up of three elements:

1. The compensation related to the effort task

2. A gain provided when taking a break

3. Less the penalty (if any)

Which are:

1. For each player, the ECU compensation related to the effort task is equal to half the total number of correct answers provided by the team during the round, times 10 .

For instance, if player 1 provided 8 correct answers and player 2 provided 5 correct answers, the gain for each player related to the effort task is $0.5 \times(8+5) \times 10=65$ ECUs

2. For each 20 second break, you will receive 6 ECU, whatever your compensation for the effort task.

3. At the end of each round, before the next round starts, the player who provided the largest number of correct answers can, if he wants to impose a fine on his partner, for an amount between 1 and 30 ECUs. The gain of the partner is reduced by that amount. One ECU in fines will cost the punisher 0.30 ECU. (No sanction is possible if players provide the same number of correct answers) 
-At the end of the experiment, the total amount in ECU will be converted into euros at the exchange rate $100 \mathrm{ECU}=2.5$ euros.

\section{Slide 8. Check questions.}

To make sure that you have understood well the rules of the game, please answer these questions:

\section{Case 1.}

During the round you got 4 right answers and your partner got 2 right answers. You took two breaks.

Your gain in ECU is:

(a) $0.5^{*}(4+2)^{*} 10+2 * 6$; (b) $(4+2)^{*} 10+2 * 6$; (c) I do not know

Case 2.

At the end of the round you got 4 right answers and your partner got 2 right answers. Can you impose a fine on your partner?

(a) Yes (b) No (c) Don't know

Can your partner impose a fine on you?

(a) Yes; (b) No; (c) Don't know

Case 3.

At the end of the round you chose to impose a fine on your partner. The amount of the fine can be:

(a) Between 1 and 10; (b) Between 1 and 30; (c) I do not know.

\section{Slide 9.}

Correct answers are:

Case 1.

-During the round you got 4 right answers and your partner got 2 right answers. You took two breaks.

-The right answer is: you have half of the total points times 10, and the compensation for the breaks $(2 \times 6$ ECUs), that is a total of $0.5(4+2) * 10+2 \times 6$

Case 2.

-You got 4 right answers and your partner got 2 right answers.

-Yes, you can impose a fine on him. Attention, this is an option; you do not need to impose a fine.

-No, he cannot impose a fine on you

Case 3.

At the end of the round you chose to impose a fine on your partner. The amount of the fine can be between 1 and 30. The payoff of your partner will be reduced by this amount.

\section{Slide 10.}

-If you have any questions, please raise your hand and address it to the administrator. -If you are sure you have understood the rules of the game, you can press the button below to launch the experiment. 
-The experiment starts when all subjects have pressed the button.

\section{Slide 11. (Main decision screen)}

Similar to "Example" in Slide 5 (but without the text on top of the screen; and the timer on the right upper corner).

\section{Slide 12. Results on task}

-Your performance: Number of counted blocks [ ], Number of right answers [NRA1], Number of breaks []

-The performance of your partner: Number of right answers [NRA2 ].

-[If NRA1 > NRA2 the computer displays] Do you want to impose a fine on the partner? -You choose: Yes // No

-If you click Yes the computer displays "choose the amount of the fine" [A=1 to 30], then

"Validate"

\section{Slide 12. Payoff for the round}

-Your partner has imposed a fine on you [or / did not impose a fine on you]

-The amount of the fine is: $[\mathrm{A}]$

-Your payoff for the round is: [ ]

\section{At the end of the experiment (after the 6 rounds) \\ Question 1.}

Please evaluate the performance of your partner:

-[very poor, poor, average, good, very good]

\section{Question 2.}

Your partner was:

-[A man, A woman, Don't know]

\section{Question 3.}

In this experiment, considering the performance of you partner, you believe that a [opposite gender partner] would have performed:

-[much worse, worse, the same, better, much better]

\section{Question 4.}

In this experiment, do you think that a [opposite gender partner] would have applied a sanction:

-[much lower, lower, identical, higher, much higher]

\section{Last slide}

Thank you for having participated in this experiment.

The total gain for the experiment is [ ] euros. 


\section{ESSEC Business School}

Avenue Bernard Hirsch

CS 50105 Cergy

95021 Cergy-Pontoise Cedex

France

Tél. + 33 (0) 134433000

Fax +33(0)134433001

www.essec.fr

ESSEC Executive Education

CNIT BP 230

92053 Paris-La Défense

France

Tél. + 33 (0)1 46924900

Fax +33(0)1 46924990

www.executive-education.essec.fr

\section{Contact:}

ESSEC Asia-Pacific

100 Victoria Street

National Library \# 13-02

Singapore 188064

Têl. +65 68849780

Fax +6568849781

www.essec.edu/asia

Research Center +33 (0)134433358 research.center@essec.fr

\section{a}

